\title{
Do Financial Markets Exhibit Chaotic Behavior? Evidence from BIST
}

\author{
Assoc. Prof. Dr. Kutluk Kağan Sümer (Istanbul University, Turkey)
}

\begin{abstract}
Knowing of the chaos theory by the economists has caused the understanding of the difficulties of the balance in economy. The applications of the chaos theory related to economy have aimed to overcome these difficulties. Chaotic deterministic models with sensitive dependence on initial conditions provide a powerful tool in understanding the apparently random movements in financial data. The dynamic systems are analyzed by using linear and/or nonlinear methods in the previous studies. Although the linear methods used for stable linear systems, generally fails at the nonlinear analysis, however, they give intuition about the problem. Due to a nonlinear variable in the difference equations describing the dynamic systems, unpredictable dynamics may occur. The chaos theory or nonlinear analysis methods are used to examine such dynamics systems. The chaos that expresses an irregular condition can be characterized by "sensitive dependence on initial conditions".

We employ four tests, viz. the BDS test on raw data, the BDS test on pre-filtered data, Correlation Dimension test and the Brock's Residual test. The financial markets considered are the stock market, the foreign exchange market. The results from these tests provide very weak evidence for the presence of chaos in Turkish financial markets. BIST, Exchange Rate and Gold Prices. In this study, the methods for the chaotic analysis of the time series, obtained based on the discrete or continuous measurements of a variable are investigated. The chaotic analysis methods have been applied on the time series of various systems.

Chaos, is the way a deterministic system can behave in a disordered manner. For example sometimes chaotic situations can be seen in the flow of a liquid passing from a smooth pipe. Once the flow rate of the fluid passes a certain value, eddies are formed and the Newton laws lose their validity. Namely now the flow is chaotic.

Although J. Henri Poincare is accepted as the father of chaos concept and theory, the most important contribution for the theory was made by Edward Lorenz who became a meteorology professor in M.I.T. in 1960. Lorenz entered data to his computer in order to prepare a simple weather forecast report and as a result showed the temperature values he found in graphics. Lorenz, restarted the function by increasing the randomly selected temperature values in small amounts that even a very sensitive thermometer cannot detect and found out that totally different functions were formed even though he expected functions would not create any difference in graphics. It was observed that the decrease and increase in graphics in long term caused a pattern like a butterfly.
\end{abstract}
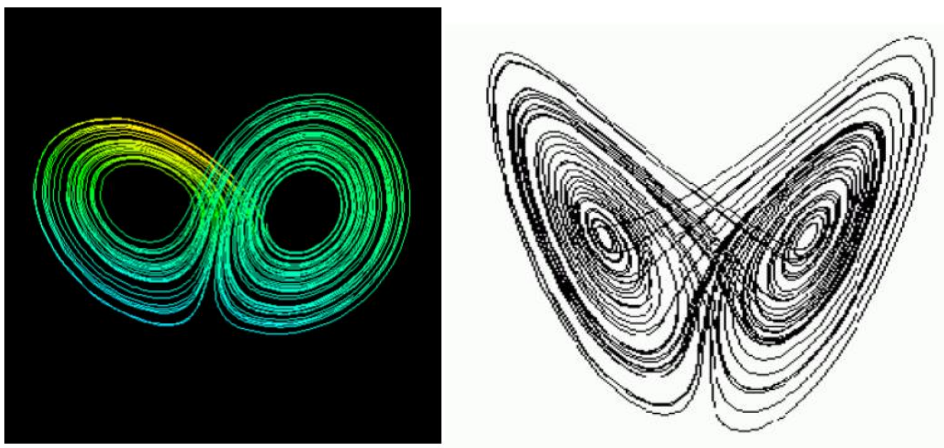

Figure 1: Lorenz Attractions

The comment Lorenz made from this result is as follows: As a result of its chaotic behavior a correct and reliable long-term weather forecast cannot pass a certain time, for this reason, in a system that shows non-periodical behavioristic characteristics is not possible.

Lorenz, tried to explain "chaos theory" by putting forth two main features of chaotic systems that look like disordered but have an internal order. After this study of Lorenz, two main characteristic features of chaotic systems that chaos theory tries to explain, looking like disorder from outside but having an internal order are clearly set forth.

The technical features of chaotic processes are as follows;

\section{Dependency on Beginning Situation}

If the beginning situation and equation of a deterministic system is known, the subsequent behavior of the system can be determined. In chaotic systems, in order to determine the development of the system throughout the time, it is necessary to know the beginning values with an infinite precision. Since chaotic systems are not linear, the error shall increase exponentially in time. 
In theory, essentially everything occurs according to time, for example; pollen production, population increase, economical changes, world ice mass etc... can be chaotic. Chaotic studies can be seen in fields like physics, chemistry, mathematics, communication, biology, physiology, sociology, economics, history, ecology, astronomy, hydraulics, atmospheric, international relations, solar systems, engineering.

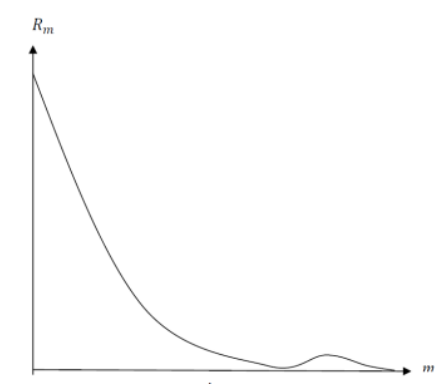

Figure 2: Chaotic Corelogram

The series in a chaotic structure shows a sensitive dependency on beginning conditions. For this reason, the relation between past and feature values is very weak. As can be seen in the Figure, according to this fact, as the delay increases the series that have autocorrelation values converging to zero are the series that have very weak relation between past and future. Consequently, it can be said that this kind of series have a chaotic structure.

\section{The Situation of Being Random.}

In a more clear statement: In fact many events in the world have a chaotic structure (everything is not linear like the way it is thought to us); like the formation of a snowball, the increase of a cigarette smoke, the development of the stems of a tree, the flight of bevy of birds, the movements of waves in the sea. So these behavior patterns conform with the laws of new science. It is claimed that in the process that cannot be set into the concept of causality of classical science and that can be named as dynamic systems, chaos would destroy determinism and brought a new horizon to the science that stuck.

Dynamic Systems and Chaos Theory, is a theory that points out the fact that minor fluctuations made in complex systems which are not linear can lead to big changes in the future. It is a theory that says prediction of events that might happen in the near future is easy, however prediction of the events that might happen in long-term can be hard. The most common example that can be given for chaos theory is butterfly affect.

The basic propositions of chaos theory can be listed as follows;

a. Order creates disorder.

b. There is an order in disorder.

c. Order comes from disorder.

d. In the new system reconciliation and dependency show themselves very shortly after the change.

e. The new order reached, develops into a new direction through a process that was organized by itself.

3. Fractal Geometry

Mandelbrot defines the "fractal" concept as geometrical shapes that the parts and the total Show similar structural characteristics. [Tosun, 2006]. From this point of view, fractal geometry, with its simplest form, can be defined as the geometry of Chaos. The shapes that have fractured dimensions, self-similar structures that give the same shape in every scale, the infinite embranchments and the resemblance of these embranchments with the main structure form the base fractal geometry. It is tried to explain the fractal structure and real nature structures with rules. These self-recurring structures cannot be understood with Oklid geometry. However, fractal geometry can solve the mystery of these shapes. Trying to simplify these structures and explain complex systems with this simplicity that is reached establish the reason for the research of fractal structures [Tosun, 2006].

The basic and simple rule of forming Fractal Shapes, is continuously repeating a rule that is accepted. Namely, if a rule is taken as fixed and continuously applied a fractal shape can be obtained. The fractal structure of WaclawSierpinski that can be seen in Figure 2 can be given as an example for this. Sierpinski forms a new triangle from the median points in an equilateral triangle. By renewing this for every triangle formed here, the triangle shapes in Figure 2 are created [Peters, 1996]. 


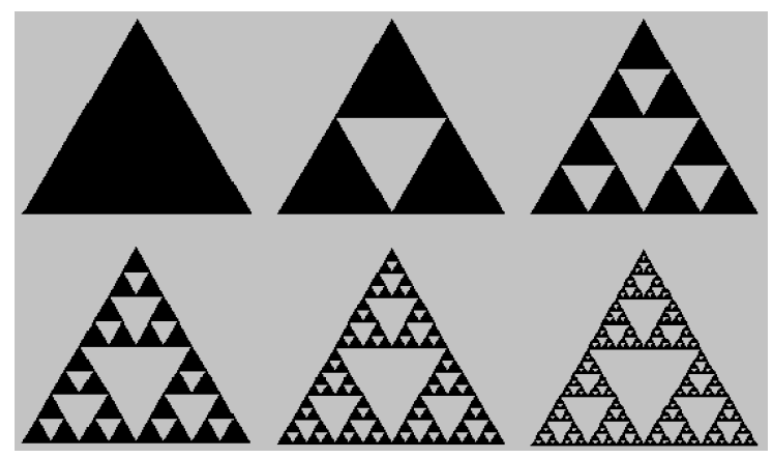

Figure 3: Sierpinskn's Fraktal Sample

Fractal time series for several grounds arises if the display time series in self-similar structures. Fractal time series time series are distributed substantially random and deterministic all the features they do not show in certain periods. Therefore, similar to the structure forms the main structure is made by chance in time series.

A series of linear fractal dimension is also quite close to 1 . Therefore, with high sharpness, the rise and fall of this size is more structure and 2 are both approaching a fractional number. This situation can be explained why the application of chaos theory to Tonis Vaga the financial markets. According to the market in the risks and rewards Vaga has a non-volatile linear structure [Vaga, 1991].Therefore fractal dimension and structure of the system is important to make a good analysis. Because this way, high returns at low risk according to market certain conditions it is possible to achieve. Similarly, investors such as Warren Buffett and George Soros, have declared in a similar way to achieve higher profits than the average over the long term [Tosun, 2006].

Attractions briefly are the pictures of the dynamic system. Accordingly, a dynamic movement is analyzed fractal geometry, work is greatly facilitated. For example, while expressing that point strange attractors stood unchanged by time the system is attractive complex mostly shaped in interesting building. Results have chaotic nature of the system; unpredictable function is a structure constituting the time series. This is equivalent to the function that vary randomly increase and decrease. Differently from each other in phase space for each different chaotic fluctuation in the system it consists of different trailers in other words. A major attraction of the chaos arising in the framework of the historical development work can be summarized as follows [Kasap ve Kurt, 2011].

- Lorenz Attraction

- Rössler Attraction

- Henon Attraction

Here in the conceptual point of view trailers contain two important points. These are attractive to himself and his form. According to the behavior of a system that is understood by fully engaged. Therefore, it is called a tow truck, but it can be described by fractal geometry attracted to strange attractors. The concept of strange attractors of chaos indispensable work have different phase space portrait for each different chaotic time series.
a) Periodic (sinüs) Signal
b) Chaotic (Lorenz) Signal
c) White Noise (Random) Signal
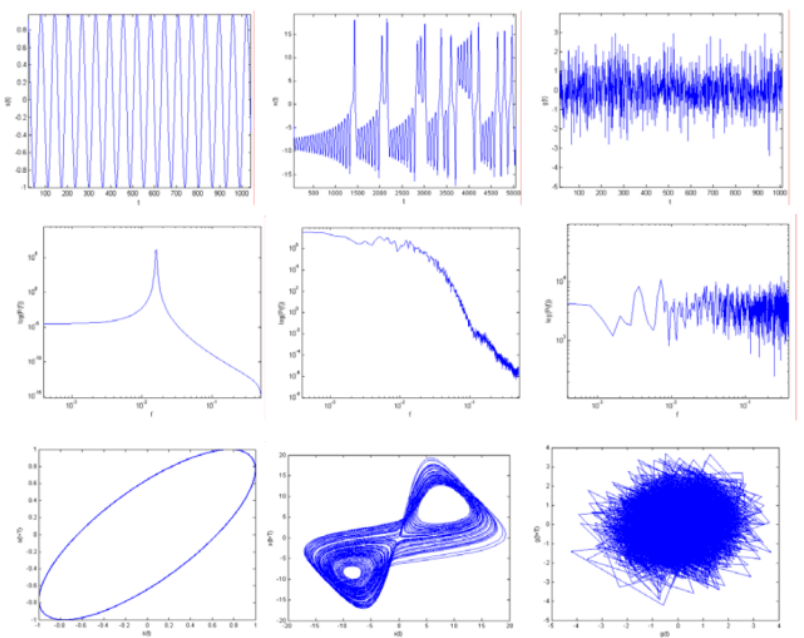

Figure 4: Periodic (Sinusoidal) (A), Chaotic (Lorenz) (B) And Noise (Random) (C) Power Spectra And Phase Of The Signal Takes In Space. Each Column from Top to Bottom, In the Form of Time Series Signal Shows Pulls the Signal Power Spectral Density and Two-Dimensional Phase Space

Analysis for Detecting the Presence of Chaos

Chaotic systems can often be expressed mathematically in two ways: 
i. For continuous systems with discrete differential or difference equations systems,

ii. with experimental data in cases where the equations are unknown.

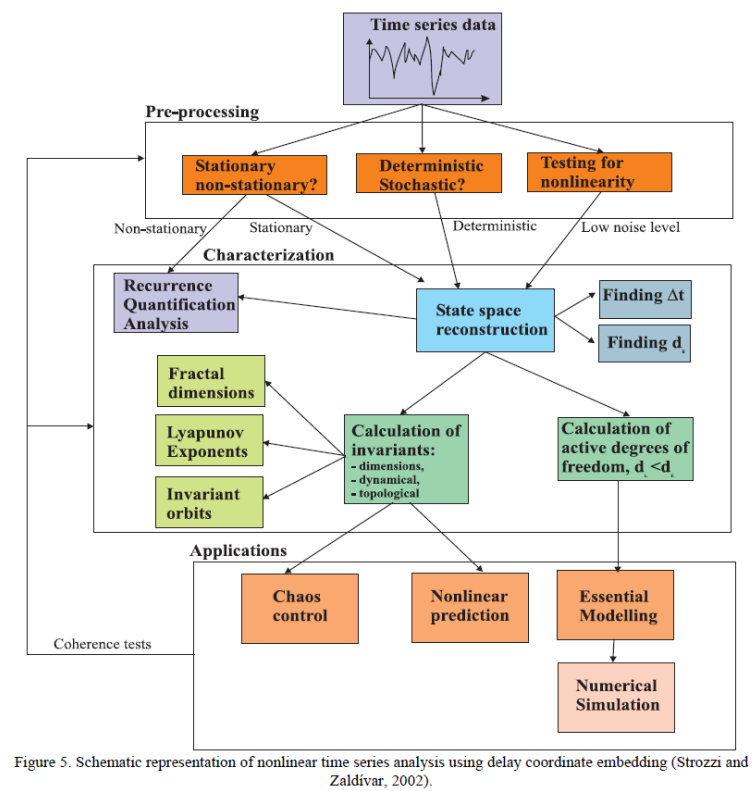

Figure 5: Schematic Representation of Nonlinear Time Series Analysis Using Coordinate Embedding (Strozzi and Zaldivar, 2002)

\section{Mutual information method}

Fraser and Swinney (1986) and Abarbanel (1996)'s proposed mutual information procedure (mutual information) is a method for measuring the information contained on each of the two time series. Here is a time line and used his delayed state. If these two series are independent of each other, mutual information value is zero.

\section{2- Embedded size}

When you start analyzing a time series can be represented in many dimensions of this series it is known as geometric and how to select the delay time. Embedded Takens Theorem (embedding theory) allows a time delay of raw data and the data of the series; she is able to determine the topological structure of a dynamic system. Embedded theorem guarantees us $\mathrm{m}$ in size in the corresponding system of the second vector [Kantz and Schreiber, 2004]. So M in size two points are very close together, $\mathrm{m}$ becomes visible in a space with larger values.

False Nearest Neighbourhood method (FNN) is an often provided by Kennel et al. (1992) a method for commonly used.

\section{Lyapunov Exponents}

The reason why chaotic systems shows non-periodic dynamics, in almost the same initial conditions of each of the phase space have different curves are exponential rate of increase. This condition is called sensitive to initial conditions. Lyapunov Exponent $\lambda$, gives a measure of sensitivity to initial conditions and phase separation is defined as the average of the local extent of the adjacent curve in space. If $\lambda$ negative different initial conditions tend to give the same output value and therefore development is not chaotic. If $\lambda$ is positive data to different output values for different initial values so it means it is a chaotic movement.

\section{Fractal Dimensions}

Fractal geometry is a term introduced by Mandelbrot in the scientific literature. Mandelbrot examined the structural integrity of natural object. At one point, a line, respectively mathematical objects such as a square or a cube zero, one, two or three-dimensional objects are known. Geometric structure of the total size gives us information about the number of objects.

\section{Detecting of Nonlinearity}

Time series of physiological, biological, created with the information obtained from real life such as mechanical systems. These periodic signals, semi-periodic, chaotic or random or be revealed to the computations described above is not entirely consist of noise, but this is a difficult process. A chaotic system is a system of low-dimensional linear and non-linearity is a necessary condition for the detection of chaos. Therefore, various methods have been developed to detect the data of the nonlinearity.

Brock, Dechert and Scheinkman (1987), an independent distribution VmT(I) similar to the true statistical measure of the departure (s) have derived normalization factor. This normalization factor is the integral of complex correlation factors of different sizes. Here utilizing BDS statistics obtained are shown as follows: 


$$
W_{m}^{T}(l)=\sqrt{T} \frac{\left[C_{m}^{T}(l)-\left[C_{m}^{T}(l)\right]^{m}\right]}{V_{m}^{T}(l)}
$$

Here, when is $\mathrm{T} \rightarrow \infty, l>0$ ve $m>1$ Under the hypotheses space for distribution $\mathrm{N}(0,1)$ converges to the distribution [Amilo and Byström, 1998]. The rejection of the null hypothesis testing procedure done here, due to the fact that with a lack of any information on The reasons for not accepting the test has trouble. In contrast, the BDS of the test's lack of distribution test with independent identical distributed errors are estimated from the general part of the parametric model that affected the implementation of the longer Brock Potter and also is shown by Lima is another factor that makes the test advantageous [Brock and Potter, 1993].

\section{Correlation integral}

Definitions of different sizes to show the complexity of dynamic systems are available. It is most commonly used in practice correlation dimension (correlation dimensions). Two reasons are indicated generally in the choice of the correlation dimension. First, similar size, attractive compared to other dimensions such as mutual information size is the scale of research in fine detail. The second reason, correlation is easier than the integration of other dimensions and can be calculated quickly [Öztürk, 2008].

\section{Application}

As can be observed, BIST-100 Return in econometric time-series break and high frequencies generated by the explosion is considered as an example of inconsistent behavior on a linear model is normally distributed.

The reason for this non-linear models, both stochastic, as well as the ability to explain this kind of behavior, which may be deterministic. On the other hand, a chaotic process, proper identification of deterministic and also completely random behavior that is impossible. Hence chaotic systems are also explained by the non-linear model. Deterministic randomness of the system and can be produced in the model, it is very important for the chaotic patterns different from the general situation in the economy.

In the study, the chaotic structure of the mutual information method for the detection, correlation integral, BDS test, Teraesvirt Neural Network Test, White Neural Network Test, and finally, Lyapunov Exponent which may be conclusive evidence of the existence of chaotic structure will be used.

To determine the structure of chaotic, would reveal the true nature of the system to be small when the frequency of the data set Kayseri / hours of data taken from the transformer in Turkey was preferred. According to this study, Kayseri / withdrawn from the transformer in Turkey hourly data collected from 1357 hours of observation values were used.

In practice, a lot of chaos for Data Analysis 5.1 (Visual Recurrence Analysis) program has benefited from the package and R Studio belonging fnonline and tserieschaos package.

\section{LEVEL MARKETS HYPOTHESIS}

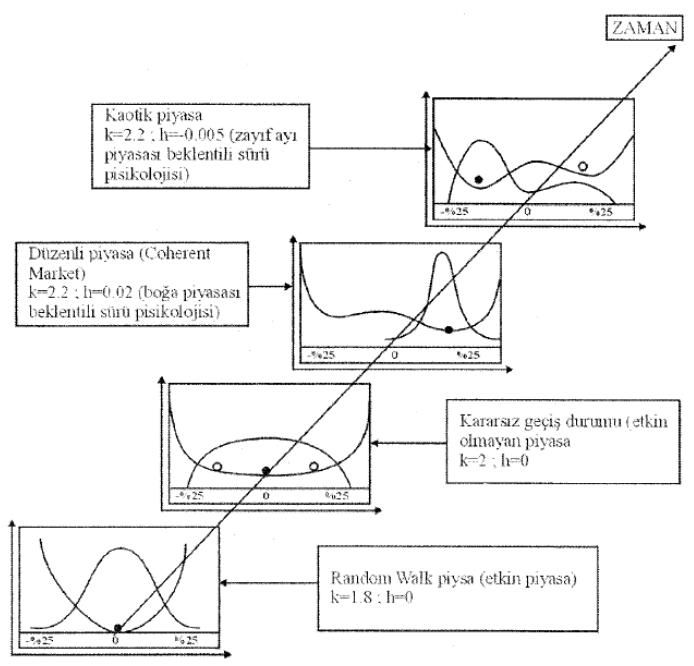

Figure 6: The Graph on The Horizontal Axis S All Returns, Vertical Axis Shows The Probability of Return. Source: Erdinç, Yaşar; Borsada Analiz, Siyasal Kitabevi, Ankara, 1998, S.65. 


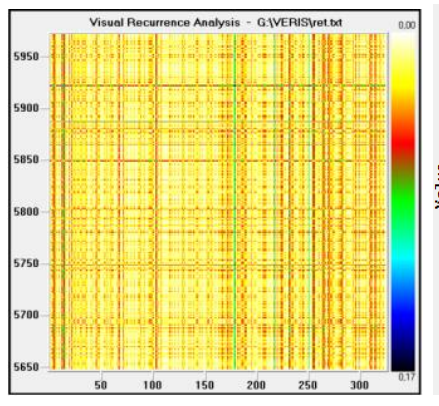

Figure 7: Visual Recurrence Analysis

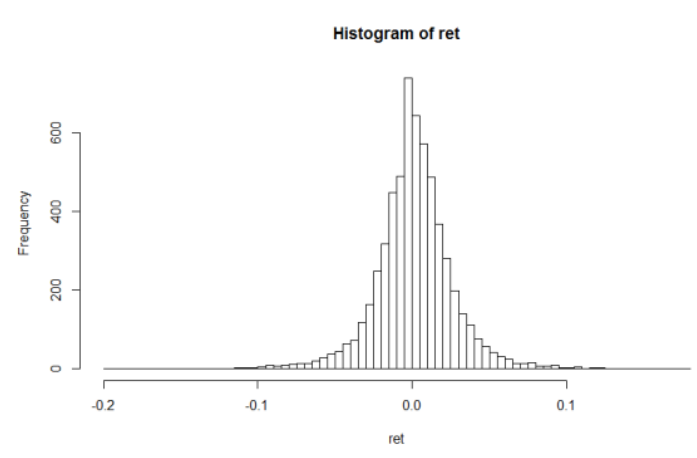

Figure 9: Histogram of Return

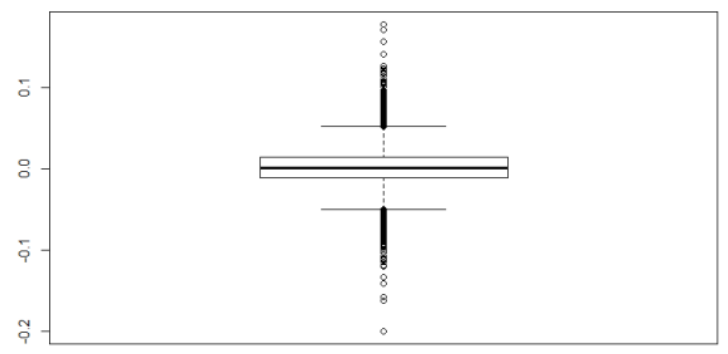

Figure 11: Distribution of Return

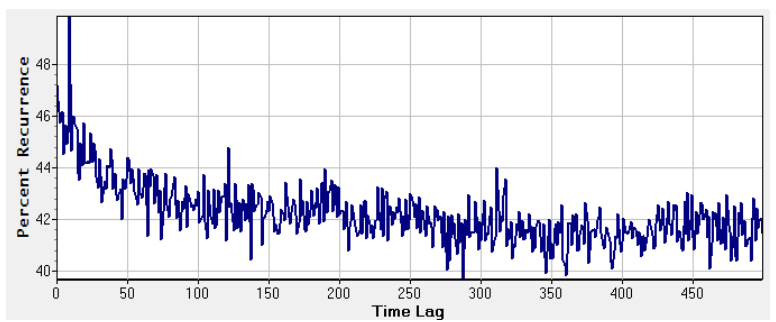

Figure 13: Percent Recurrence

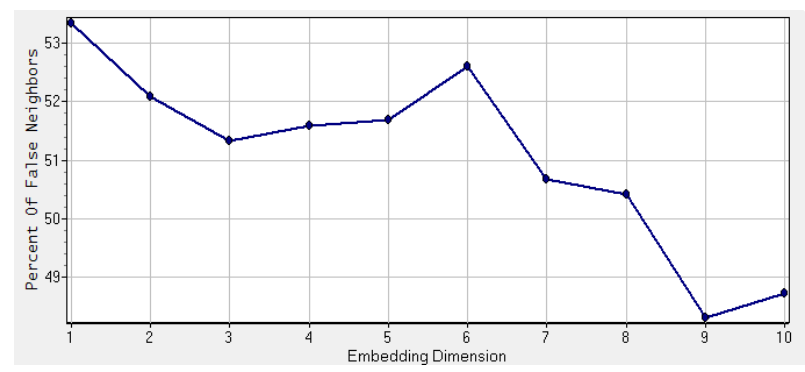

Figure 15: False Neighbours
Figure 8: Analysis of Return

Correlogram for RET

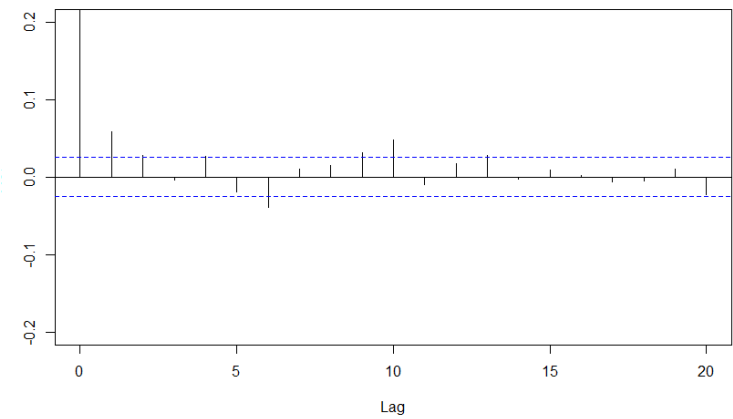

Figure 10: Correlogramı of Return

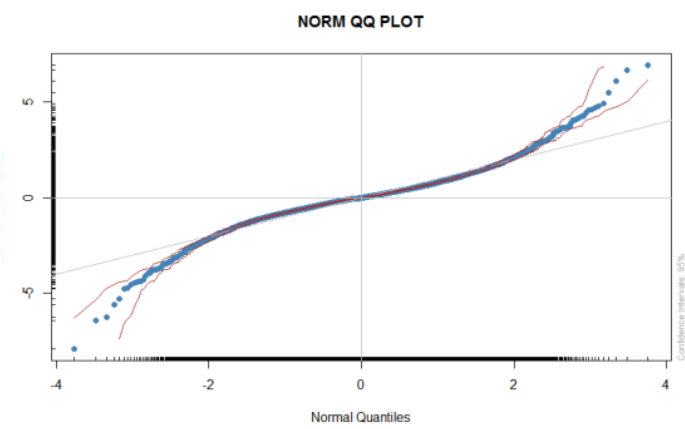

Figure 12: $Q Q$ Plot of Return

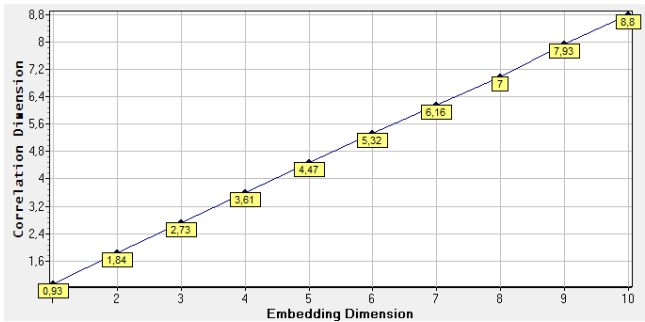

Figure 14: Embebed Dimension

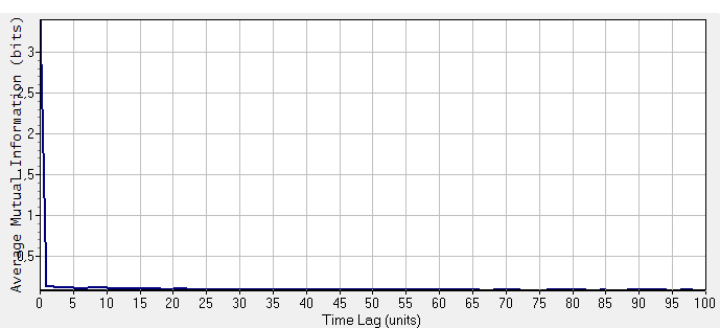

Figure 16: Mutal Information 


\begin{tabular}{|l|l|l|}
\hline BDS Test & $\begin{array}{l}\text { STATISTIC: } \\
\text { eps[1] } \mathrm{m}=2: 16.1014\end{array}$ & $\begin{array}{l}\text { P VALUE: } \\
\text { eps[1] } \mathrm{m}=2:<2.2 \mathrm{e}-16\end{array}$ \\
Test Results: & eps[1] $\mathrm{m}=3: 23.3923$ & eps[1] $\mathrm{m}=3:<2.2 \mathrm{e}-16$ \\
PARAMETER: & eps[2] $\mathrm{m}=2: 18.4324$ & eps[2] $\mathrm{m}=2:<2.2 \mathrm{e}-16$ \\
Max Embedding Dimension: 3 & eps[2] $\mathrm{m}=3: 25.4771$ & eps[2] $\mathrm{m}=3:<2.2 \mathrm{e}-16$ \\
eps[1]: 0.013 & eps[3] $\mathrm{m}=2: 19.5218$ & eps[3] $\mathrm{m}=2:<2.2 \mathrm{e}-16$ \\
eps[2]: 0.025 & eps[3] $\mathrm{m}=3: 25.4946$ & eps[3] $\mathrm{m}=3:<2.2 \mathrm{e}-16$ \\
eps[3]: 0.038 & eps[4] $\mathrm{m}=2: 20.097$ & eps[4] $\mathrm{m}=2:<2.2 \mathrm{e}-16$ \\
eps[4]: 0.051 & eps[4] $\mathrm{m}=3: 24.7045$ & eps[4] $\mathrm{m}=3:<2.2 \mathrm{e}-16$ \\
& & \\
\hline
\end{tabular}

Table 1: BDS Test

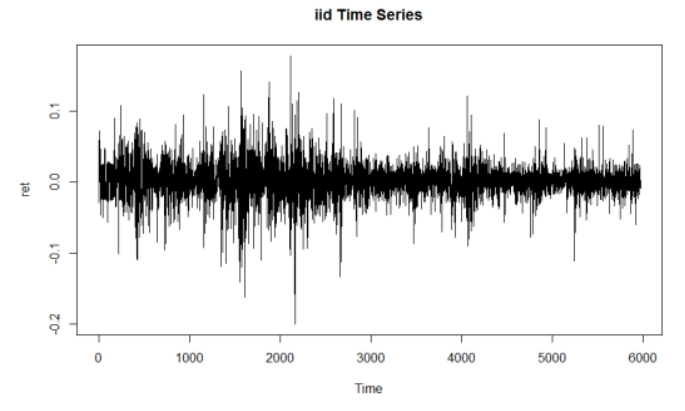

Figure 17: iid Time Series

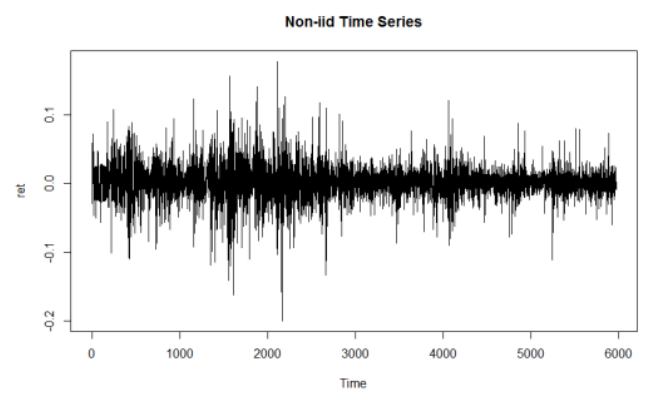

Figure 18: non iid Time Series

\begin{tabular}{|l|l|}
\hline Teraesvirta Neural Network Test & White Neural Network Test \\
Test Results: & Test Results: \\
PARAMETER: & PARAMETER: \\
lag: 1 & lag: 1 \\
m|df: 2 & q: 10 \\
t-lag-m|df: 5969 & range: 4 \\
STATISTIC: & qstar|df: 2 \\
Chi-squared: 28.3039 & t-lag-qstar|df: 5969 \\
F: 14.1784 & STATISTIC: \\
P VALUE: & Chi-squared: 28.2216 \\
Chi-squared: $7.143 \mathrm{e}-07$ & F: 14.1371 \\
F: $7.194 \mathrm{e}-07$ & P VALUE: \\
& Chi-squared: $7.443 \mathrm{e}-07$ \\
& F: $7.496 \mathrm{e}-07$ \\
\hline
\end{tabular}

Table 2: Neural Network Tests

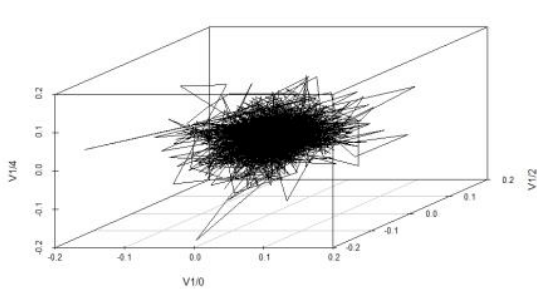

Figure 19: 3D Phase Space

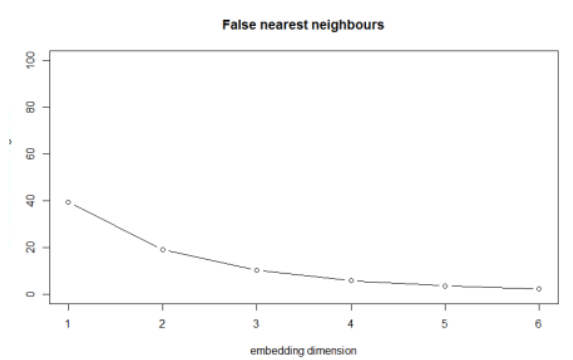

Figure 20: False Nearest Neighbours 


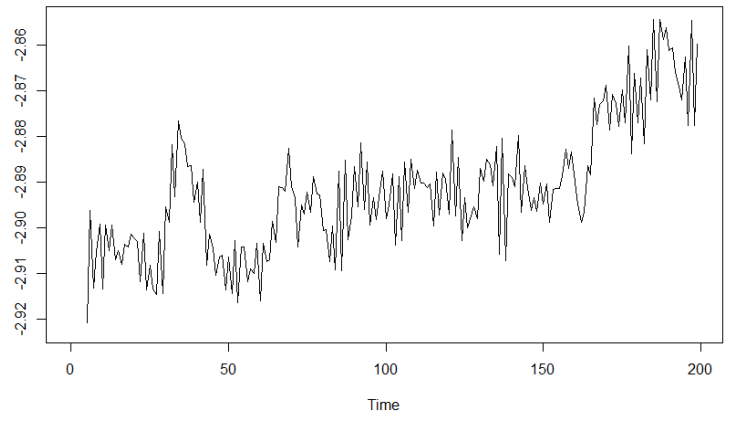

Figure 21: Space-Time Plot

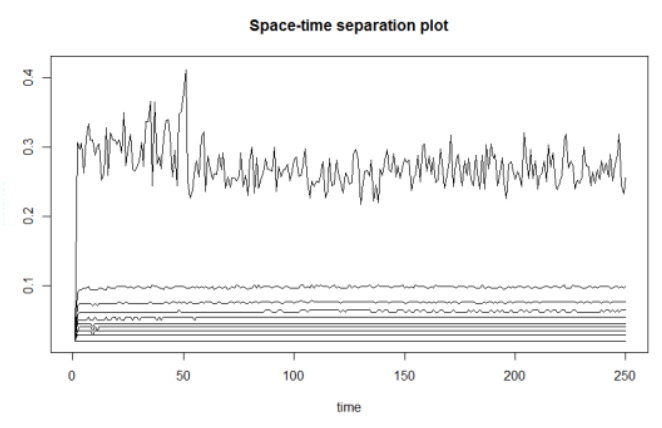

Figure 22: Space-Time Separation Plot

\section{Result}

All the tests and outcomes lends support to the chaos. So Istanbul is not possible to give the bridge crossing linear modeling. Relations can only be investigated by nonlinear equations.

Linear chaotic prediction will be as follows. Model is not possible to make predictions about spikes.

Forecasting the BIST-100 is still one of the big challenges facing financial engineers and econometricians. For the past two decades, many models have been developed to identify the data generating process of the financial econometrics and to produce more accurate forecasts.

Advances in the computing technology have enabled econometricians to develop and to work with nonlinear and complex models with intensive computations more easily. These models seem to be more suitable for estimation and, in particular, forecasting very complex series such as the BIST-100.

In this paper, we examined the statistical features of the BIST-100 return series, using the daily data. The traditional view is that the demand variations can be explained by a trend, history, stochastic factors, or a combination of them.

However, if the data generating process of the return is chaotic, the traditional modeling for estimation and forecasting would be misleading. To shed more lights on the underlying data generating process of the return, we carried out various tests for deterministic chaos. The tests included correlation dimension, BDS, ANN, WNN and Lypunov Exponent. Give the restrictions of the tests, and the fact that each test is developed based on certain characteristics of the chaotic process, the results obtained from them individually cannot be conclusive. Therefore, applying all available tests and comparing the results would allow us to get more robust results.

For this reason, alternative estimation methods as kernel regression and we were to use the Nearest Neighbour Estimate results will be as follows.

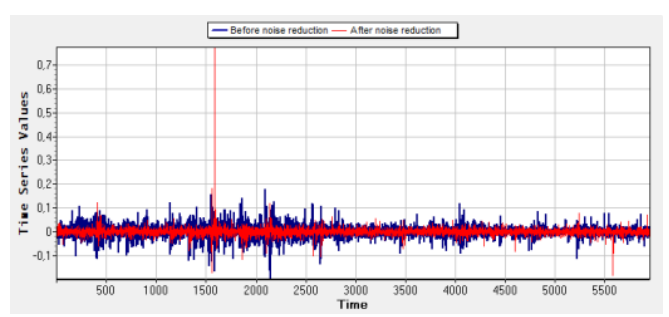

Figure 23: Error Reduction Plot

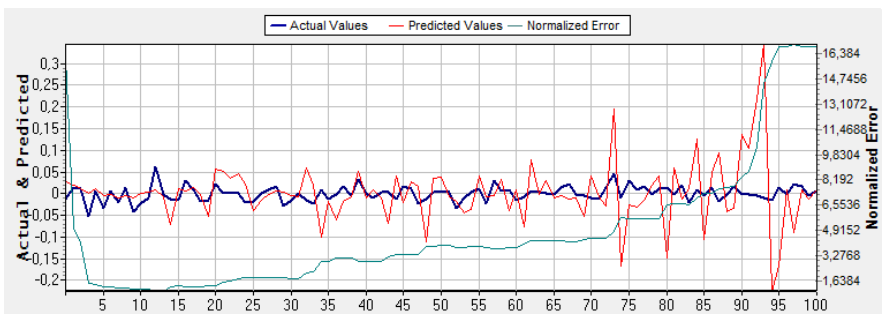

Figure 24: Chaotic Estimation Plot

\section{References}

- $\quad$ Akay, M., Nonlinear Biomedical Signal Processing, Dynamic Analysis and Modelling, Volume II, IEEE Pres, 2000.

- $\quad$ Aktaş, H., \& Kozoğlu, M. ,"Haftanın Günleri Etkisinin İstanbul Menkul Kıymetler Borsası'nda GARCH Modeli ile Test Edilmesi”, Finans Politik \& Ekonomik Yorumlar , 37-45 (2007).

- $\quad$ and Strange Attractors", Physica D, Cilt 8, 435- 444, 1983.

- Awrejcewicz, J., Dzyubak, L. ve Grebogi, C., “A Direct Numerical Method for Quantifying Regular and Chaotic Orbits", Chaos, Solitons and Fractals, Cilt 19, No 3, 503-507, 2004.

- $\quad$ Barnett, W. A. ,"Martingales, Nonlinearity and Chaos",Department of Economics, Campus Box(1998).

- Brock, W., \& Potter, S. ,"Nonlinear Time Series and Macroeconometrics",Handbook of Statistics, 195-229 (1993). 
- Brock, W., Dechert, W., \& Scheinkmann, J. ,"A Test for Independence based on the Correlation Dimension",Wisconsin Madison - Social Systems(1987).

- $\quad$ Brock, W., Lakonishok, J., \& LeBaron, B. ,"Simple Technical Trading Rules and the Stochastic Properties of Stock Returns", The Journal of Finance, 1731-1764 (1992).

- Brock, William A. Is the business cycle characterized by deterministic chaos? Journal of monetary economics 22 (1988) 71-90

- Cao, L., "Practical Method for Determinig the Minimum Embedding Dimension of a Scalar Time Series", Physica D, Cilt 110, No 1, 43-50, 1997.

- Derya Yılmaz, Nihal Fatma Güler; Kaotik Zaman Serisinin Analizi Üzerine Bir Araştırma; Gazi Üniv. Müh. Mim. Fak. Dergisi ; Cilt 21, No 4, 759-779, 2006

- $\quad$ Erdinç, Yaşar; Borsada Analiz, Siyasal Kitabevi, Ankara, 1998, s.65.

- Fernanda Strozzi, Eugénio Gutiérrez Tenrreiro, Carlo Noè, Tommaso Rossi, Massimiliano

- Frrat, U., "Kaotik Zaman Serilerinin Yapay Sinir Ağlarıyla Kestirimi: Deprem Verisi Durumu", Yüksek Lisans Tezi, Yıldız Teknik ÜniversitesiFen Bilimleri Enstitüsü Elektronik ve Haberlesme Anabilim Dalı, İstanbul (2006).

- Grassberger, P., \& Procaccia, I. ,"Characerization of Strange Attractors",Physical Review Letters, 346-349 (1983).

- Hentschel, H.G.E. ve Procaccia, I., "The Infinite Number of Generalized Dimensions of Fractals

- $\quad$ Kalra, S. ,"Global Volatility and Forex Returns in East Asia",IMF Working Paper, 08/208 (2008).

- Kantz, H., \& Schreiber, T. ,"Nonlinear Time Series Analysis",United Kingdom: Cambridge University Press (2004).

- $\quad$ Kasap, P., \& Kurt, D. ,"Karmaşanın Bilimi Kaos",Nobel Yayınevi , Ankara (2011).

- Kennel, M., Brown, R., \& Abarbanel, H. ,"Determining Embedding Dimension for Phase-Space Reconstruction Using a Geometrical Construction",Physics Review, 340-353 (1992).

- Kennel, M.B., Brown R. ve Abarbanel H.D.I., "Determining Embedding Dimension for Phase- Space Reconstruction Using a GeometricalConstruction”, Phys. Rev. A, Cilt 45, 3403-3411, 1992.

- Mandelbrot, B.B., Fractals: Form, chance, and dimension, W.H. Freeman, San Francisco, 1997.

- $\quad$ Öztürk, A. ,"Doppler İşaretlerinin Kaotik Ölçütlerle Sınıflandırılması",Doktora Tezi,Selçuk Üniversitesi Fen Bilimleri Enstitüsü Elektrik-Elektronik Mühendisliği Anabilim Dalı, Konya (2008).

- Özün, Alper; "Kaos Teorisi, Hisse Senedi Getirilerindeki Doğrusal Olmayan Davranışlar, Zayıf İşlem ve GelişenPiyasalarda Piyasa Etkinliği: İMKB Örneği" Y1l.:3, Sayı:9, Ocak/Şubat/Mart 1999.

- Perron, P. (1989), The great crash, the oil price shocks and unit root hypothesis Econometrica 57 1361-1401

- Pindyck, Robert. (1999), The Long-Run Evolution of Energy Prices the Energy Journal, Vol.20, and No.2

- Saeed Moshiri, Testing for deterministic chaos in futures crude oil price;Does neural network lead to better forecast?, May 2004, University of Allameh Tabatabaie

- Selçuk Kendirli, Portföy Yönetiminde Kaos Teoremi; Journal of İstanbul Kültür University 2006/2 pp. 171 180

- Serati, José-Manuel Zaldívar Comenges; Applicatıon Of Non-Linear Time Series Analysis Techniques To The Nordic Spot Electricity Market Data; Liuc Papers N. 200, Serie Tecnologia 11, Marzo 2007

- $\quad$ Sprott, J.C., Chaos and Time-Series Analysis, Oxford University Pres, 2003.

- Strozzi, F., Zaldívar, J. M., \& Zbilut, J. P. 2002. Application of nonlinear time series analysis techniques to high frequency currency exchange data, Physica A 312, 520-538.

- Şahika Gökmen, Zaman Serilerinde Kaos Ve Forex Üzerine Uygulama, Yüksek Lisans Tezi, Gazi Üniversitesi Fen Bilimleri Enstitüsü, 2012

- Tosun, T. ,"Türev Araçlar, Kaos Teorisi ve Fraktal Yapıların Vadeli İșlem Zaman Serilerinde Uygulanması",Yüksek Lisans Tezi,T.C. Marmara Üniversitesi Bankacılık ve Sigortacılık Enstitüsü Sermaye Piyasası ve Borsa , İstanbul (2006).

- Vaga, Tonis; Profiting From Chaos, McGraw Hill, New York, 1994, s.21.

- Yalamova, R., Qi, L., Wang, L., Chen, Y., Mathews, S., \& Gong, G. ,"Detecting Chaos in Financial Time Series", Tech. Print (2006).

- Yu, D., Lu, W. ve Harrison, R.G., "Detecting Dynamical Nonstationarity in Time Series Data”, Chaos, Cilt 9, No 4, 1999. 